\title{
Novos mecanismos pelos quais o exercício físico melhora a resistência à insulina no músculo esquelético
}

\author{
New mechanisms by which physical exercise improves \\ insulin resistance in the skeletal muscle
}

José Rodrigo Pauli ${ }^{1,2}$, Dennys Esper Cintra ${ }^{2}$,

Claudio Teodoro de Souza ${ }^{3}$, Eduardo Rochette Ropelle ${ }^{2}$

\section{RESUMO}

O prejuízo no transporte de glicose estimulada por insulina no músculo constitui um defeito crucial para o estabelecimento da intolerância à glicose e do diabetes tipo 2. Por outro lado, é notório o conhecimento de que tanto o exercício aeróbio agudo quanto o crônico podem ter efeitos benéficos na ação da insulina em estados de resistência à insulina. No entanto, pouco se sabe sobre os efeitos moleculares pós-exercício sobre a sinalização da insulina no músculo esquelético. Assim, esta revisão apresenta novos entendimentos sobre os mecanismos por meio dos quais o exercício agudo restaura a sensibilidade à insulina, com destaque ao importante papel que proteínas inflamatórias e a S-nitrosação possuem sobre a regulação de proteínas da via de sinalização da insulina no músculo esquelético. Arq Bras Endocrinol Metab. 2009;53(4):399-408.

Descritores

Exercício; resistência à insulina; inflamação; músculo esquelético

\begin{abstract}
Insulin resistance of skeletal muscle glucose transport is a key-defect for the development of impaired glucose tolerance and type 2 diabetes. However, it is known that both an acute bout of exercise and chronic endurance exercise training can bring beneficial effects on insulin action in insulin-resistant states. However, little is currently known about the molecular effects of acute exercise on muscle insulin signaling in the post-exercise state in insulin-resistant organisms. This review provides new insight into the mechanism through which acute exercise restores insulin sensitivity, highlighting an important role for inflammatory proteins and S-nitrosation in the regulation of insulin signaling proteins in skeletal muscle. Arq Bras Endocrinol Metab. 2009;53(4):399-408.

Keywords

Exercise; insulin resistance; inflammation; skeletal muscle
\end{abstract}

' Departamento de Biociências, Faculdade de Educação Física, modalidade Saúde, Universidade Federal de São Paulo (Unifesp), Santos, SP, Brasil ${ }^{2}$ Departamento de Clínica Médica, Faculdade de Ciências Médicas, Universidade Estadual de Campinas (Unicamp), Campinas, SP, Brasil

${ }^{3}$ Laboratório de Fisiologia e Bioquímica do Exercício. Programa de Pós-graduação em Ciências da Saúde, Universidade do Extremo Sul Catarinense (Unesc), Criciúma, SC, Brasil

Correspondência para: José Rodrigo Pauli Departamento de Biociências, Curso de Educação Física Modalidade Saúde

Av. Dona Ana Costa, 95 - Vila Mathias

11060-001 - Santos, SP, Brasil

rodrigosere@yahoo.com.br

\section{INTRODUÇÃO}

$\mathrm{O}$ músculo esquelético representa aproximadamente $40 \%$ da massa corporal total e exerce papel primordial no metabolismo da glicose (1). Esse tecido é responsável por aproximadamente $30 \%$ do consumo energético, além de ser um dos principais tecidos responsáveis pela captação, liberação e estocagem de glicose (2). Trabalhos realizados nas últimas décadas demonstraram claramente que o exercício físico aumenta a captação de glicose pelo músculo esquelético (3-6). Além disso, recentemente, foi demonstrado que a redução de peso corporal associada ao aumento da atividade física em indivíduos com risco aumentado para desenvolver diabetes reduz em $58 \%$ a incidência dessa doença (7). Assim, atualmente, o exercício físico é considerado uma das pedras angulares tanto da prevenção como do tratamento do diabetes tipo 2 . Os mecanismos moleculares envolvidos no aumento da captação de glicose muscular vêm sendo intensamente pesquisados. Nesta revisão, serão abordados alguns aspectos dessa fascinante área que está se desenvolvendo rapidamente. 


\section{EXERCÍCIO FÍSICO E SINALIZAÇÃO DA INSULINA: PERSPECTIVA HISTÓRICA}

As primeiras evidências do efeito favorável do processo de contração muscular na captação de glicose surgiram em 1887, quando Chauveau e Kaufamann reportaram redução da quantidade de glicose proveniente da musculatura do masseter de cavalos enquanto eles mastigavam o feno (8). Quatro décadas depois, foi demonstrado que a insulina tem o mesmo efeito do exercício na indução da captação de glicose pelos músculos (9). Tais pesquisas deram origem a uma série de investigações que buscaram elucidar a possível interação entre insulina e o exercício na regulação da captação de glicose. Em 1972, Bjorntorp e cols. demonstraram melhora da tolerância à glicose e níveis de insulina menores em homens que participavam regularmente de esportes competitivos em comparação aos controles. O mesmo grupo de pesquisadores evidenciou que mulheres hiperinsulinêmicas e obesas apresentaram os níveis de insulina plasmático diminuídos após seis semanas de treinamento físico (10-11). Tais descobertas hipotetizaram que o exercício regular poderia aumentar a sensibilidade à insulina no músculo e em outros tecidos, ideia confirmada apenas na década de 1980 por Carl Mondon e cols. mediante experimento com roedores (12).

Com a confirmação do papel favorável do exercício físico na ação metabólica da insulina, inúmeros estudos buscaram desvendar os mecanismos moleculares por meio dos quais o exercício atua como estimulador fisiologicamente relevante ao transporte de glicose em diferentes tecidos. Cientistas têm evidenciado, nos últimos anos, que o exercício tem efeito importante nos mecanismos moleculares de captação de glicose no músculo esquelético tanto em indivíduos saudáveis como nos portadores de resistência à insulina. No entanto, para que sejam compreendidos os mecanismos moleculares por meio dos quais o exercício físico contribui para melhorar a captação de glicose e prevenir e tratar o diabetes tipo 2, é necessário, inicialmente, descrever como a insulina transmite seu sinal celular desde o receptor até os efetores finais.

\section{VIA DE TRANSMISSÃO DO SINAL DE INSULINA}

A insulina é um hormônio polipeptídico anabólico produzido pelas células-beta do pâncreas, cuja síntese é ativada pelo aumento dos níveis circulantes de glicose e aminoácidos após as refeições. Sua ação ocorre em vários tecidos periféricos, incluindo fígado, músculo esquelético e tecido adiposo. Seus efeitos metabólicos imediatos incluem: aumento da captação de glicose, principalmente em tecido muscular e adiposo, aumento da síntese de proteínas, ácidos graxos e glicogênio, bem como bloqueio da produção hepática de glicose, lipólise e proteólise, entre outros.

A sinalização intracelular da insulina começa com sua ligação a um receptor específico de membrana, uma proteína heterotetramérica com atividade quinase intrínseca, composta por duas subunidades alfa e duas subunidades beta, denominado receptor de insulina (IR) (13). A ativação do IR resulta em fosforilação em tirosina de diversos substratos, incluindo substratos do receptor de insulina 1 e 2 (IRS-1 e IRS-2) (14-15). A fosforilação das proteínas IRS cria sítios de ligação para outra proteína citosólica, denominada fosfatidilinositol 3-quinase (PI3q), promovendo sua ativação (16). A PI3q é importante na regulação da mitogênese, na diferenciação celular e no transporte de glicose estimulada pela insulina. A ativação da PI3q aumenta a fosforilação em serina da proteína quinase $\mathrm{B}(\mathrm{Akt})$ e isso permite o transporte de glicose no músculo e no tecido adiposo, através da translocação da proteína Glut-4 para a membrana celular (17). Portanto, a ativação da Akt resulta na translocação do Glut-4 para a membrana, permitindo a entrada de glicose por difusão facilitada. Os Glut-4 são os principais responsáveis pela captação da glicose circulante nos humanos. Atividades físicas praticadas regularmente estimulam a translocação dos Glut-4 e promovem captação de glicose e redução da sua concentração sanguínea. Além disso, o sinal transmitido pela PI3q ativa a síntese de glicogênio no fígado e no músculo, e da lipogênese no tecido adiposo $(14,18)$. Portanto, a via PI3q/Akt tem um importante papel nos efeitos metabólicos da insulina. O esquema resumido das etapas de sinalização da insulina envolvida na captação de glicose encontra-se apresentado na figura 1.

\section{BASES MOLECULARES DO EXERCíCIO FÍSICO E A HOMEOSTASE DA GLICOSE}

O exercício físico aumenta a captação de glicose no músculo esquelético por diferentes mecanismos moleculares. Evidências experimentais demonstraram que a contração muscular não necessariamente estimula a fosforilação do IR e dos seus substratos (IRS-1 e IRS-2) em resíduos de tirosina, ou da enzima chave da via a PI3q. Tal confirmação foi estabelecida por experimentos in vitro, nos quais o bloqueio farmacológico da 


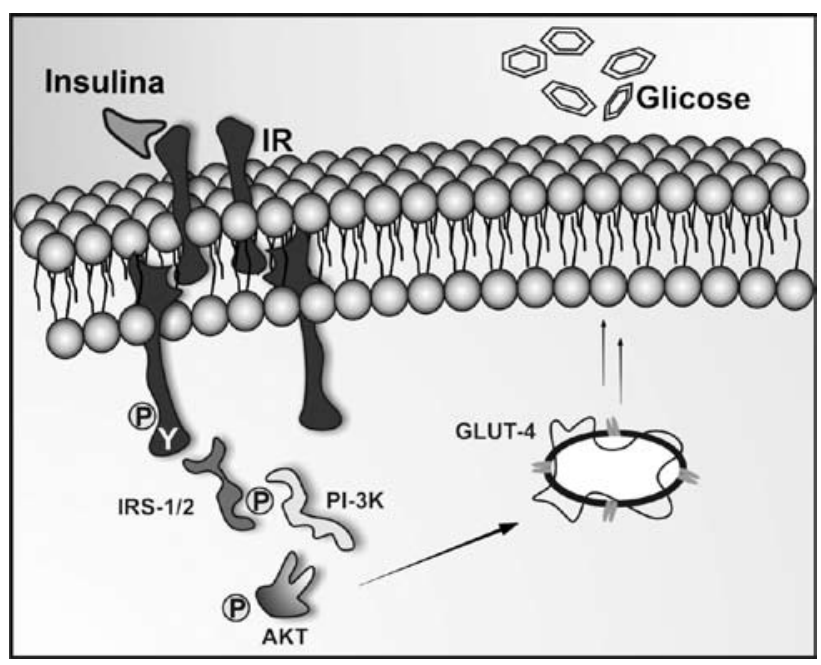

Figura 1. Via de sinalização da insulina na captação de glicose. A insulina, ao se ligar ao seu receptor de membrana, promove a autofosforilação da subunidade beta em resíduos de tirosina e desencadeia uma cascata de sinalizações que convergem para as vesículas que contêm GLUT-4, promovendo o seu transporte para a membrana celular.

PI3q através do wortmannin não bloqueou o transporte de glicose estimulada por contração do músculo esquelético (19). Portanto, existem diferentes formas de condução do sinal para que ocorra o transporte de glicose mediada pela insulina ou pelo exercício no músculo esquelético. Foi então que houve a descoberta de uma enzima chave de resposta à contração muscular denominada AMPK (proteína quinase ativada por AMP), que também estimula o transporte de glicose no músculo esquelético, mas por meio de um mecanismo independente de insulina.

A ativação da AMPK é resultado do decréscimo do estado energético celular. $\mathrm{Na}$ situação em que a relação AMP:ATP aumenta, ocorre uma mudança conformacional na molécula, deixando-a suscetível à fosforilação e ativação pela AMPK quinase (AMPKK) (20). A AMPK fosforilada ativa vias que geram o aumento de ATP, tais como a oxidação de ácidos graxos, ao mesmo tempo que desativa as vias anabólicas que consomem o ATP, como a síntese de ácidos graxos. Esse aumento da atividade da AMPK em resposta a uma necessidade em gerar ATP durante o exercício físico promove a translocação das vesículas contendo Glut-4, facilitando o transporte de glicose para o músculo de maneira semelhante à da insulina, embora isso ocorra por vias de sinalização diferentes e independentes. Nessa situação, a redução da malonil-CoA permite o aumento da ação da carnitina acil transferase 1 , que aumenta a eficiência do transporte de ácidos graxos para as mitocôndrias e consequente oxidação (21).
No entanto, o mecanismo de transporte de glicose através da via de sinalização da AMPK não parece ser o único mecanismo responsável por esse processo metabólico. De maneira semelhante, existem inúmeras outras moléculas envolvidas nesse mecanismo de sinalização durante o exercício. O aumento na concentração do íon cálcio no interior da célula, a atividade da óxido nítrico sintase (NOS) e a síntese por ela de óxido nítrico (NO), o aumento na concentração de bradicinina ou até mesmo a hipóxia podem estimular a captação de glicose através do aumento da translocação do Glut-4 para a membrana durante a contração muscular (22-25).

Além disso, novas evidências científicas mostram que o exercício físico pode, além dos efeitos positivos sobre a via de sinalização dependente de insulina (IR/IRSs/ PI3-q/Akt) e/ou independente de insulina (via AMPK e/ou outras biomoléculas), também beneficiar o indivíduo obeso com resistência à insulina por diminuir a expressão e/ou atividade de proteínas inflamatórias de efeito negativo à ação da insulina (26-28).

\section{OBESIDADE E RESISTÊNCIA À INSULINA}

O preciso mecanismo envolvido na causa da resistência à insulina ainda não é totalmente conhecido. Contudo, muitos estudos têm demonstrado que alterações moleculares na via de sinalização da insulina, principal responsável pela ativação da translocação do transportador de glicose (Glut's) à membrana plasmática, são determinantes no estado de resistência à insulina em tecidos periféricos, como o músculo esquelético e o tecido adiposo (29-32). No entanto, deve-se levar em consideração que a relevância de mecanismos relacionados ao prejuízo da translocação de vesículas ricas em Glut's é específica para tecidos cuja forma Glut-4 é expressa de maneira relevante.

O Glut-4 é o transportador de insulina-dependente mais abundante nas membranas celulares do músculo esquelético, cardíaco e tecido adiposo. Sem o estímulo hormonal, a concentração de Glut-4 na membrana é muito baixa, estando armazenadas em vesículas citoplasmáticas. Após a estimulação pela insulina, esses transportadores são translocados para a membrana e o transporte de glicose é aumentado. No entanto, em algumas células, como os hepatócitos, os neurônios e as hemácias, a glicose é capaz de se difundir para o interior da célula na ausência de insulina e, portanto, os mecanismos moleculares relacionados ao prejuízo no sinal da insulina e, consequentemente, na captação de glicose não se aplicam (33-34). 
Por outro lado, na obesidade ocorrem alterações em diversos pontos da via de transdução do sinal da insulina, com redução na concentração e atividade quinase do IR, na concentração e fosforilação do IRS-l e IRS-2, na atividade da PI3q, na translocação dos Glut's e na atividade das enzimas intracelulares. Isso atenua consequentemente a captação de glicose nos tecidos insulino-dependentes, como músculo esquelético e tecido adiposo. O impacto negativo do aumento da quantidade de tecido adiposo nos organismos sobre a sensibilidade à insulina pode ser claramente demonstrado na maioria dos indivíduos, assim como o aumento da sensibilidade à insulina observada com a redução do peso corporal e com exercício físico (35-37).

Inicialmente, os ácidos graxos livres (AGLs) foram implicados nesse processo. A presença de elevados níveis de AGLs circulantes está associada a uma menor fosforilação em sítios específicos e à menor ativação de proteínas-chave da via da insulina (IRSs/PI3q). Evidências científicas apontam uma relação direta entre AGLs e resistência à insulina, que pode ser decorrente do acúmulo de triglicerídeos e metabólitos derivados de ácidos graxos (diacilglicerol, acetil-CoA e ceramidas) no músculo e no fígado (38-39). O aumento desses metabólitos provenientes da oxidação das gorduras no músculo é capaz de provocar a ativação da PKC e/ou da kinase IkB, e também de causar fosforilação em serina do IR e de seus substratos, sendo estes importantes mecanismos que explicam a relação entre acúmulo de gordura tecidual e resistência à insulina (38).

Contudo, nos últimos anos, vários fatores regulatórios produzidos por adipócitos (adipocinas) foram descritos, bem como o papel que desempenham no desenvolvimento de resistência à insulina. A seguir, será apresentado como alguns desses fatores regulam negativamente a ação da insulina, agindo tanto no receptor de insulina quanto em moléculas pós-receptor, para posterior compreensão dos efeitos do exercício físico na atenuação desse processo.

\section{INFLAMAÇÃO E RESISTÊNCIA À INSULINA}

A hipótese de que a inflamação em tecidos metabólicos pode contribuir para o desenvolvimento de resistência à insulina teve origem em 1993, quando se deu a descoberta de que também o tecido adiposo era capaz de produzir TNF- $\alpha$, uma citocina inflamatória que prejudica a via de sinalização da insulina. Posteriormente, desvendou-se que outras citocinas inflamatórias sub- jacentes ao TNF- $\alpha$ provocariam resistência à insulina induzida por obesidade (40).

Recentes estudos evidenciam que a origem dessas citocinas inflamatórias na obesidade decorre da migração de macrófagos para os adipócitos $(30,32)$; em paralelo, ácidos graxos provenientes da dieta, principalmente os de origem animal, são capazes de ativar proteínas de membrana celulares denominadas TLR-4, um dos tipos de toll like receptors que funciona como mediador da via inflamatória com consequências negativas para ações da insulina em tecidos metabólicos.

Recém-descritos, os receptores da família TLR (toll like receptors) desempenham uma conexão importante entre o sistema imune inato e o sistema metabólico (41). Evolutivamente preservados, esses receptores sensíveis a patógenos desempenham importante atividade próinflamatória, como esperado. Entretanto, esses mesmos receptores, principalmente os TLR-4, são sensíveis também a nutrientes, como os ácidos graxos. A ingestão elevada de gordura na dieta pode ativar esses receptores, ativando também, mesmo na ausência de patógenos, uma resposta inflamatória capaz de interferir nos sinais mediados pelos hormônios controladores da fome e gasto energético, resultando em obesidade (42).

Tal tentativa de interpretação e analogia pode ser reforçada por experimentos com roedores, nos quais camundongos com mutação genética dessa proteína utilizam melhor a glicose, apresentam menor depósito de gordura e não desenvolvem resistência à insulina mesmo quando submetidos a uma dieta rica em gordura. Portanto, ao se ligarem a esse receptor de membrana celular, alguns ácidos graxos acionam proteínas de resposta inflamatória, incluindo a JNK (c-jun N-terminal kinase) e IкK (Ikappa kinase), que bloqueiam a ação da insulina (Figura 2). Esses resultados permitem considerar que os TLR-4 sejam justamente a conexão que faltava entre ingestão de dietas ricas em gordura saturada e o desenvolvimento de resistência à insulina (30-32).

A ativação dos substratos intermediários da via de sinalização do TNF- $\alpha$, como a serina quinase JNK, pode interferir na funcionalidade dos substratos do receptor de insulina, o IRS-1 e IRS-2. Uma vez fosforilados em serina pela JNK, a possibilidade de serem fosforilados em tirosina pelo receptor de insulina fica comprometida, o que contribui para a resistência à transdução do sinal da insulina através dessa via. Outra via pró-inflamatória que pode levar à fosforilação em serina de subs-

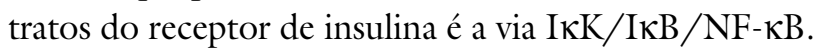
Essa via pode ser ativada pelo TNF- $\alpha$, mas também por 


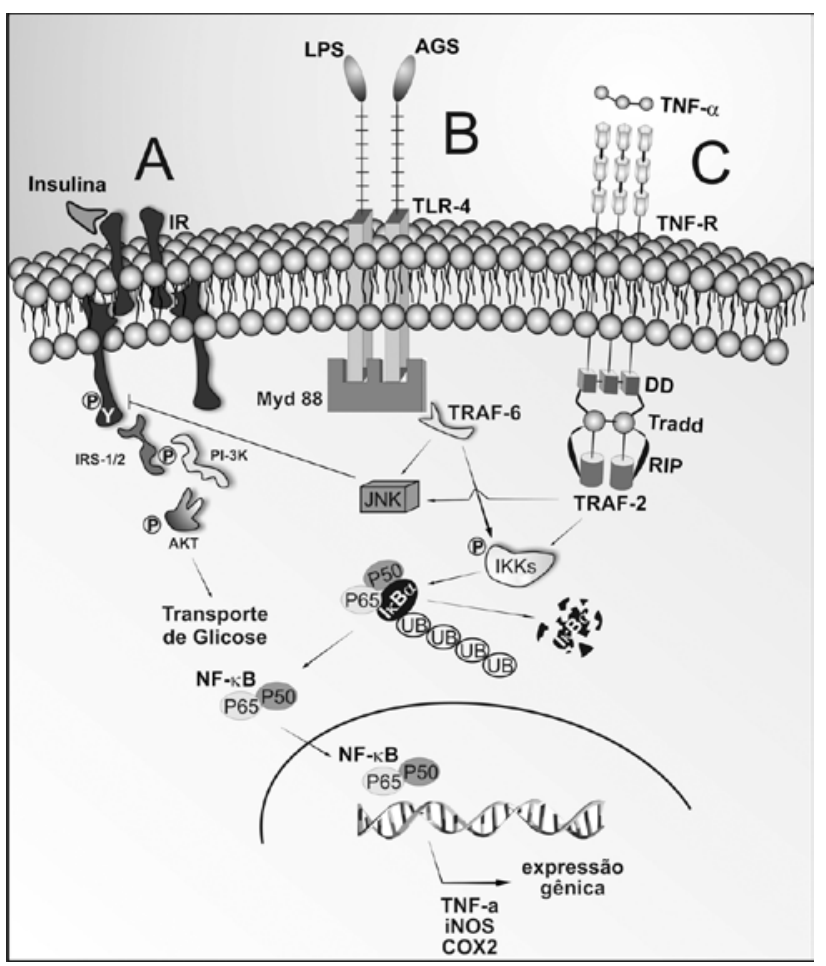

Figura 2. Inflamação e resistência à insulina. A ativação de quinases na obesidade, especialmente IKappaB Kinase (IKK) e c-jun aminoterminal kinase (JNK), ressalta a sobreposição das vias metabólicas e inflamatórias: essas são as mesmas quinases ativadas na resposta imune inata pelo TLR (toll-like receptor) em resposta ao LPS e aos ácidos graxos (AGS). A IkKß pode interferir na sinalização de insulina através de pelo menos duas vias: primeiro, ela pode fosforilar diretamente os substratos do receptor de insulina (IRS-1 e IRS-2) em resíduos de serina; segundo, ela pode ativar indiretamente o NFkB, um fator de transcrição que, entre outros alvos, pode estimular a produção de vários mediadores inflamatórios, incluindo o TNF- $\alpha$, iNOS e COX2. A JNK ativada tanto pela via do TLR-4 como pelo TNF- $\alpha$ também pode interferir negativamente na sinalização da insulina, fosforilando o IRS-1 e o IRS-2 em serina. (A) via de sinalização da insulina; (B) via de sinalização do TLR-4; e (C) via de sinalização do TNF- $\alpha$.

outras citocinas pró-inflamatórias como IL-1ß (interleucina $1 \beta$ ). A ativação do IKK promove a dissociação do complexo I $\mathrm{KB} / \mathrm{NF}-\kappa \mathrm{B}$, mas também pode induzir a fosforilação em serina dos IRS, que compromete a transdução do sinal da insulina através dessa cascata. Em animais com obesidade induzida por dieta rica em gordura, o bloqueio da atividade da IKK $\beta$ através da administração de altas doses de salicilatos resultou na melhora da sensibilidade à insulina (43-44).

Estudo recente de Carvalho-Filho e cols. descreveu outro mecanismo por meio do qual se instaura a disfunção celular e o prejuízo na ação da insulina quando animais saudáveis são submetidos a uma dieta rica em gordura, ganham peso excessivamente e tornam-se obesos (45). Recentemente, demonstrou-se que o óxido nítrico (NO) produzido pela proteína óxido nítrico sintase (NOS) é um importante sinalizador intracelular capaz de modificar a função proteica por diversos mecanismos em etapas pós-transcripcionais, incluindo nitrosilação, nitração e S-nitrosação. A S-nitrosação ocorre pela adição de um grupamento $\mathrm{NO}$ ao radical tiol $(\mathrm{S}-\mathrm{H})$ de um resíduo de cisteína, formando um nitrosotiol ( $\mathrm{S}-\mathrm{NO}$ ). Nesse estudo, foi demonstrado que drogas doadoras de NO, nitrosoglutationa (GSNO) ou nitrosocisteína (CISNO) e a própria indução da iNOS seriam capazes de provocar S-nitrosação e com isso modificar a função de proteínas envolvidas na via de sinalização da insulina (45).

Nos últimos dez anos demonstrou-se que, além de suas ações vasodilatadoras, o NO tem também papel fundamental como sinalizador intracelular, controlando várias funções da célula e modulando inclusive a apoptose (46). As NO-sintases (NOS) são as principais fontes intracelulares de $\mathrm{NO}$ e dividem-se em três subtipos. A NO sintase neuronal (nNOS ou NOS 1) e a NO sintase endotelial (eNOS ou NOS 3) são cálcio dependentes e exercem funções biológicas importantes em seus respectivos tecidos, como regulação da apoptose neuronal, no caso da nNOS, e vasodilatação, no caso da eNOS. A NO sintase induzível (iNOS ou NOS 2) já foi descrita em detalhe, não é cálcio dependente e pode ter sua expressão induzida a partir do estímulo com interleucinas ou lipopolissacarídeo (LPS) (47). Uma vez produzido, o NO pode modificar a função proteica por meio de processos químicos diferentes, que dependem principalmente da disponibilidade de espécies oxidantes e da concentração de NO liberado (45).

Carvalho-filho e cols. observaram, ainda, indução de iNOS em dois modelos de resistência à insulina, na obesidade induzida por dieta hiperlipídica e no camundongo diabético ob/ob (obesidade induzida por deficiência em leptina) (48). Nesses dois modelos, a sinalização da insulina pela via IR/IRS-1/Akt estava diminuída, e os níveis de S-nitrosação dessas proteínas encontravam-se aumentados no músculo esquelético. Determinou-se, assim, que a S-nitrosação de proteínas envolvidas na transmissão do sinal da insulina seria um novo mecanismo molecular de resistência à insulina associado à indução da iNOS. Ao descobrir tais conexões, imaginou-se uma estratégia de ação: reduzir a resistência à insulina bloqueando a ação da iNOS, caminho que se mostrou promissor em estudos preliminares feitos em laboratório (48).

Portanto, a ativação dessas proteínas na obesidade, especialmente IKK, JNK e iNOS, ressalta a sobreposição das vias metabólicas e inflamatórias: essas são as mesmas moléculas que são ativadas na resposta imune inata pelo TLR-4 em resposta aos LPS e outros pro- 
dutos microbianos. Fortalecendo essa hipótese, experimentos com oligonucleotídeo antisense contra TLR-4 mostraram que, ao desativar esse receptor das células de camundongos diabéticos, ocorreu a redução de um tipo de célula de defesa do sangue (macrófagos) (32). Essa é uma possível conexão entre a obesidade e uma inflamação de baixa intensidade em todo o organismo e, geralmente, é observada em indivíduos que estão acima do peso considerado saudável.

Além disso, existem outros reguladores negativos da via de transdução do sinal de insulina que estão estreitamente relacionados ao aumento do programa próinflamatório, incluindo a mTOR (mammalian Target Of Rapamycin) que é capaz de fosforilar o IRS-1 em serina. A SOCS (Suppressors Of Cytokine Signaling), cujos genes são alvos das vias da JNK e IKK, também está implicada na resistência à insulina promovida pelo TNF- $\alpha$. Isso mostra que diversas proteínas pró-inflamatórias estão elevadas na obesidade e trazem como consequência a resistência à ação da insulina e outras alterações metabólicas $(26,29,45)$.

Portanto, fica evidente que diversos fatores, atuando conjuntamente ou de forma independente, podem regular negativamente a ação da insulina, agindo tanto no receptor quanto em moléculas pós-receptor. Em síntese, inúmeras moléculas bioquímicas provenientes dos adipócitos ou dos macrófagos na condição de obesidade podem provocar a ativação de serina-quinases e/ou outras moléculas, especialmente a IKK, JNK e iNOS, capazes de fosforilar moléculas em resíduos de serina ou causar nitrosilação em proteínas como o IRS-l e IRS-2, inibindo a sinalização da insulina. Vejamos, a seguir, como o exercício físico pode exercer modulação sobre algumas dessas proteínas, confirmando seu papel positivo na prevenção e no tratamento do DM2.

\section{EFEITOS ANTI-INFLAMATÓRIOS DO EXERCÍCIO NA OBESIDADE E RESISTÊNCIA À INSULINA}

Diferentes estudos apontam uma forte associação entre a prática de atividade física e a redução do processo inflamatório decorrente da obesidade (28-49). O aumento do tecido adiposo desempenha papel determinante no quadro de resistência à insulina, aumentando de duas a três vezes os níveis séricos de citocinas pró-inflamatórias como, por exemplo, o TNF- $\alpha$. Nesse contexto, parece lógico entender que o exercício passa a desempenhar um papel anti-inflamatório por reduzir a gordura corporal e, consequentemente, a produção de citocinas pró-inflamatórias. No entanto, estudos em roedores e em seres humanos revelaram que o exercício físico pode reduzir os níveis de citocinas pró-inflamatórias sem que haja alteração do peso corporal. Pedersen e cols. estudaram os efeitos anti-inflamatórios do exercício agudo em indivíduos saudáveis. Os autores relataram que indivíduos que receberam baixas doses de uma endotoxina (Escherichia coli) apresentaram um grau de inflamação sistêmica similar ao observado em indivíduos obesos. No entanto, em um grupo de indivíduos previamente exercitados, a endotoxina foi incapaz de gerar processo inflamatório observado no grupo não exercitado (49). Além disso, estudos em voluntários obesos também mostraram que uma única sessão de exercício é capaz de reduzir os níveis séricos de TNF- $\alpha$ e de proteína-C reativa sem alteração do peso corporal total $(50)$.

Apesar de a ação anti-inflamatória do exercício físico estar bem documentada, pouco se sabe como são produzidas, no interior das células, as respostas anti-inflamatórias mediadas pela atividade física. Evidências experimentais e alguns trabalhos com humanos sugerem que a resposta anti-inflamatória observada no músculo esquelético após sessão aguda de exercício ocorra por meio de mecanismos distintos (26-27). Em ratos obesos induzidos por dieta rica em gordura, uma única sessão de natação reduziu a fosforilação da JNK, bloqueou a via IKK/NFKB, reduziu a fosforilação do IRS-1 em serina e atividade da PTP-1B no músculo gastrocnêmio e restabeleceu a sensibilidade à insulina 16 horas após o término do exercício (26). A PTP-1B é uma das tirosina-fosfatases mais estudadas, exerce efeitos negativos sobre a sinalização da insulina, efeitos mediados pela desfosforilação do IR e do IRS-1. De maneira concordante, a inibição farmacológica ou o tratamento com oligonucleotídeo antisense da PTP-1B resultaram em aumento na fosforilação do IR e do IRS-1 (51-52). O camundongo geneticamente modificado que não expressa PTP $1 \mathrm{~B}$ apresenta maior sensibilidade à insulina do que seu controle quando submetido a tratamento com dieta hiperlipídica (53).

Tal tentativa de interpretação e analogia pode ser reforçada por experimentos com humanos, em que a sessão aguda de exercício físico se mostrou eficiente na redução da fosforilação da JNK e no bloqueio da via

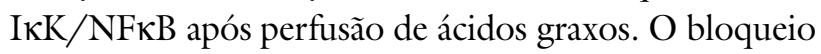

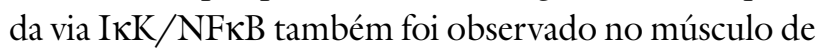
pacientes diabéticos, e esse bloqueio ocorreu pela menor

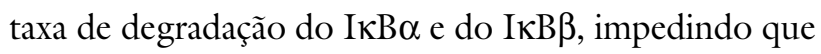
o fator de transcrição $\kappa \mathrm{B}(\mathrm{NF}-\kappa \mathrm{B})$ iniciasse a transcrição 
de proteínas pró-inflamatórias. Dessa forma, o bloqueio dessa via inflamatória através do exercício físico foi responsável por diminuir os níveis séricos de TNF- $\alpha$ nesses pacientes (54). Outro efeito positivo acontece por meio da redução da expressão de iNOS e S-nitrosação de proteínas da via de sinalização da insulina.

\section{EXERCíCIO FÍ́SICO E A S-NITROSAÇÃO}

Em recente pesquisa, ficou demonstrado que o exercício físico pode melhorar agudamente a sensibilidade à insulina em ratos submetidos a uma dieta rica em gordura. Tal fato se deve, no mínimo em parte, à reversão da $S$-nitrosação de proteínas-chave na sinalização da insulina no músculo esquelético através de uma sessão de exercício de natação (27). Ratos Wistar obesosinduzidos por dieta rica em gordura exibiram menor sensibilidade à insulina, constada pela menor taxa de desaparecimento da glicose durante o teste de tolerância à insulina em relação aos controles. Além disso, houve uma significativa redução na fosforilação do IR, IRS-1 e Akt no músculo gastrocnêmio desses animais. Por conseguinte, quando esses animais foram submetidos a um protocolo de exercício de duas sessões de três horas de natação separadas por um intervalo de 45 minutos de recuperação, resultados satisfatórios em relação à captação de glicose foram evidenciados. $\mathrm{O}$ aumento na taxa de desaparecimento da glicose ao final do teste de tolerância à glicose e o significativo aumento na fosforilação das proteínas IR, IRS-1 e Akt estimulada por insulina revelaram a ação favorável da sessão aguda de exercício que perdurou por 16 horas.

A S-nitrosação do IR, IRS-1 e Akt se mostrou inversamente relacionada à fosforilação e à ativação, sendo significativamente aumentada nos animais que se alimentaram com dieta rica em gordura e diminuída nos animais que foram submetidos ao exercício agudo de natação. No entanto, isso foi mais substancialmente pronunciado duas horas após o término do esforço, quando a restauração da sinalização da insulina foi maior (27).

Para confirmação de tais fatos, uma série de experimentos adicionais foi realizada em laboratório. Ratos Wistar que receberam dieta rica em gordura foram tratados com doador de NO (S-nitrosoglutatione, GSNO) ou com inibidor da iNOS $\left(l-N^{6}-(l\right.$-iminoethyl)lysine $(L-$ nil)) previamente ao exercício de natação. Duas horas após o exercício, a sensibilidade à insulina nos animais obesos induzidos por dieta hiperlipídica tratados com GSNO teve redução similar aos animais obesos que não foram submetidos ao protocolo de exercício. Essa redução na sensibilidade à insulina foi associada à redução na fosforilação e aumento na S-nitrosação do IR, IRS-1 e Akt. Por outro lado, a inibição da atividade da iNOS (mas não a expressão proteica) $\mathrm{com}_{\mathrm{L}}{ }_{\mathrm{L}} \mathrm{NIL}$ restaurou a sensibilidade à insulina de maneira similar à verificada nos animais exercitados, ocorrendo também aumento da fosforilação e diminuição da S-nitrosação das proteínas da sinalização da insulina. Além disso, não houve efeito aditivo da inibição da iNOS pelo fármaco com o exercício físico. Coletivamente, esses resultados sugerem que alterações na S-nitrosação são fatores importantes envolvidos na mudança da sinalização e sensibilidade à insulina induzidos por dieta e exercício físico (27).

Investigações subsequentes foram realizadas para descobrir o possível mecanismo por meio do qual o exercício físico reduz a expressão de iNOS. Uma hipótese possível envolve a ativação da AMPK. Dados da literatura indicam que a ativação da AMPK reduz a produção de NO mediada pela iNOS (55). Como o exercício físico é capaz de ativar a AMPK (56-57), isso explicaria a melhora da sensibilidade à insulina entre os animais obesos exercitados.

Ao avaliar a via de sinalização da AMPK, verificou-se redução na ativação da AMPK em ratos alimentados com dieta hiperlipídica, a qual foi restaurada a níveis controles com a realização do exercício físico (27). Uma vez que a AMPK pode suprimir a expressão de iNOS, esses resultados sugerem que, em adição ao papel de aumentar a oxidação de ácidos graxos e a captação de glicose, o aumento na atividade da AMPK por meio do exercício pode contribuir potencialmente para o aumento na sensibilidade à insulina pela redução indireta na S-nitrosação de proteínas da via de sinalização da insulina. Para a confirmação dessa hipótese, experimentos foram realizados de maneira tempo-dependente, nos quais se avaliaram a ativação da AMPK e a expressão da iNOS após o término do exercício físico. Demonstrouse, então, que a redução nos níveis de AMPK fosforilada é acompanhada por decréscimo na captação de insulina e aumento na expressão de iNOS. Os resultados desse experimento devem ser encarados como mais uma evidência da hipótese de que a ativação da AMPK após a sessão aguda de exercício é importante para a supressão da indução de iNOS em ratos obesos. Curiosamente, ratos obesos induzidos por dieta apresentam menor expressão de AMPK (57). Por outro lado, ratos obesos exercitados regularmente tiveram seus níveis de AMPK normalizados aos seus pares controles (57). Tal fato 
confirma o efeito do exercício em estimular a expressão e a atividade da AMPK no músculo esquelético.

É fundamental enfatizar, no entanto, que o exercício induz a síntese das isoformas neuronal e endotelial da enzima óxido nítrico sintase (nNOS e eNOS), e não somente da iNOS. Contudo, é preciso compreender que o efeito do NO na sensibilidade à insulina é dose-dependente e depende também da enzima geradora de NO, que é expressa em diferentes sítios (58-59). Por exemplo, o aumento da síntese de NO pela eNOS em ratos saudáveis pelo exercício físico aumenta a captação de glicose (58). No entanto, em nosso experimento, avaliouse uma condição de obesidade induzida por dieta rica em gordura saturada na qual a síntese de NO pela iNOS é pronunciada e se associa à resistência à insulina.

Além disso, uma limitação em nosso estudo, na teoria proposta de sensibilização à insulina pela prática do exercício físico, é que a iNOS normalmente não é expressa no músculo esquelético (59) e somente é induzida em condição de resistência à insulina, como na obesidade induzida por dieta rica em gordura saturada. No entanto, o exercício pode prover melhoras na ação da insulina em músculos saudáveis. Por essa razão, essa teoria pode não suprir uma explicação universal e, por isso, é provável que esse seja apenas um dos diversos fatores envolvidos na melhora da sensibilidade à insulina induzida pelo exercício na obesidade induzida por dieta.

\section{CONSIDERAÇÕES FINAIS}

Essas novas descobertas demonstraram que o exercício físico pode atuar por diferentes mecanismos intracelulares, sendo uma ferramenta importante na melhora da sinalização da insulina em organismos saudáveis ou com resistência à insulina. Na condição de resistência à insulina associada à obesidade induzida por dieta rica em gordura, pesquisas revelam que o exercício físico é capaz de modular proteínas inflamatórias de efeito negativo no sinal de insulina. A atenuação na atividade da JNK, IאK e iNOS são alguns novos mecanismos moleculares possíveis por intermédio dos quais o exercício melhora o sinal da insulina e a captação de glicose (Figura 3). No entanto, os resultados encontrados pelos diversos estudos carecem de investigações continuadas, uma vez que a duração e a magnitude dos efeitos na sinalização da insulina são variáveis, dependendo do tipo, da duração e da intensidade de exercício e do modelo de obesidade induzida, sem se descartar a possibilidade de os efeitos serem decorrentes de outros fatores e envolverem outras vias moleculares. Uma das possibilidades talvez esteja associada a mudanças hemodinâmicas induzidas pelo exercício. É conhecido que uma única sessão de exercício diminui a atividade simpática e aumenta o fluxo sanguíneo muscular no período após o exercício. É interessante notar que, durante a hiperinsulinemia perante uma única sessão de exercício, a atividade simpática é menor e a vasodilatação muscular, maior. Essas e outras mudanças hemodinâmicas podem, também, contribuir para a reversão da resistência à insulina (60). Apesar da necessidade de se definirem muitas outras etapas da ação do exercício em vias de sinalização intracelular, todas essas descobertas abrem novas perspectivas para a compreensão do efeito do exercício sobre a captação de glicose.

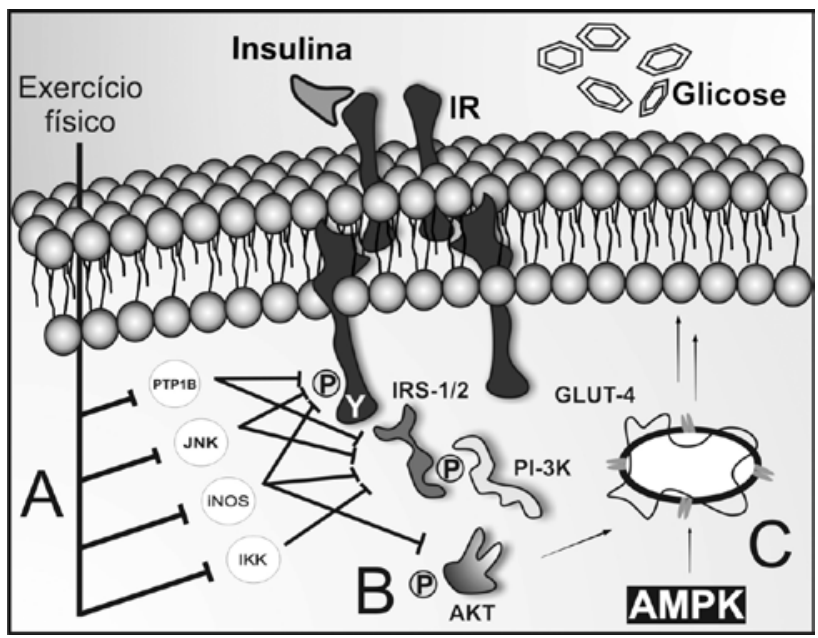

Figura 3. Novos mecanismos de ação do exercício na resistência à insulina induzida por obesidade. 0 exercício físico reduz a expressão e/ou atividade de proteínas intracelulares de efeito negativo sobre a via de sinalização da insulina, por exemplo, PTP1B, JNK, IKK e iNOS, e com isso aumenta a sensibilidade à insulina e melhora a captação de glicose na obesidade (A). A melhora no metabolismo da glicose em indivíduos exercitados deve-se ainda ao efeito do exercício de aumentar a translocação do Glut-4 por vias moleculares distintas, mediado por insulina (via IR/ IRSs/PI3q/Akt) (B) e/ou via AMPK (C) para a membrana do músculo esquelético, independente da perda de peso corporal.

Declaração: os autores declaram não haver conflitos de interesse científico neste estudo.

\section{REFERÊNCIAS}

1. Smith AG, Muscat GE. Skeletal muscle and nuclear hormone receptors: implications for cardiovascular and metabolic disease. Int J Biochem Cell Biol. 2005;37(10):2047-63.

2. Nuutila P, Koivisto VA, Knuuti J, Ruotsalainen U, Teras M, Haaparanta $\mathrm{M}$, et al. Glucose-free fatty acid cycle operates in human heart and skeletal muscle in vivo. The J Clin Invest. 1992;89(6):1767-74.

3. James DE, Burleigh KM, Kraegen EW, Chisholm DJ. Effect of acute exercise and prolonged training on insulin response to intravenous glucose in vivo in rat. J Appl Physiol. 1983;55(6):1660-4. 
4. Eriksson J, Tuominen J, ValleT, Sundberg S, Sovijarvi A, Lindholm $\mathrm{H}$, et al. Aerobic endurance exercise or circuit-type resistance training for individuals with impaired glucose tolerance? Horm Metab Res. 1998;30(1):37-41.

5. Kennedy JW, Hirshman MF, Gervino EV, Ocel JV, Forse RA, Hoenig SJ, et al. Acute exercise induces GLUT4 translocation in skeletal muscle of normal human subjects and subjects with type 2 diabetes. Diabetes. 1999;48(5):1192-7.

6. Luciano E, Carneiro EM, Carvalho CR, Carvalheira JB, Peres SB, Reis MA, et al. Endurance training improves responsiveness to insulin and modulates insulin signal transduction through the phosphatidylinositol 3-kinase/Akt-1 pathway. Eur J Endocrinol. 2002;147(1):149-57

7. Knowler WC, Barret-Connor E, Fowler SE, Hamman RF, Lachin $\mathrm{JM}$, Walker EA, et al. Reduction in the incidence of type 2 diabetes with lifestyle intervention or metformin. $\mathrm{N}$ Engl J Med. 2002;346(6):393-403.

8. Chauveau A, Kaufamann M. Expériences pour la determination du coefficient de l'activité nutritive et respiratoire des muscles en respos et en travail. C R Hebd Seances Acad Sci. 1887;104(1):1126-32.

9. Burn JH, Dale HH. On the location of action of insulin. J Physiol. 1924;59(6):164-92.

10. Bjorntorp P, De Jounge K, Sjostrom L, Sullivan L. The effect of physical training on insulin production in obesity. Metabolism. 1970;19(8):631-8.

11. Bjorntorp P, Fahlen M, Grimby G, Gustafson A, Holm J, Renstrom $P$, et al. Carbohydrate and lipid metabolism in middle-aged, physically well-trained men. Metabolism. 1972;21(11):1037-44.

12. Mondon CE, Dolkas CB, Reaven GM. Site of enhanced insulin sensitivity in exercise-trained rats at rest. Am J Physiol. 1980;239(3):E169-77.

13. Patti ME, Kahn CR. The insulin receptor: a critical link in glucose homeostasis and insulin action. J Basic Clin Physiol Pharmacol. 1998;9(2-4):89-109.

14. Pessin JE, Saltiel AR. Signaling pathways in insulin action: molecular targets of insulin resistance. J Clin Invest. 2000;106(2)165-9.

15. White MF. The IRS-signalling system: a network of docking proteins that mediate insulin action. Molecular Cell Biochemistry. 1998;182:3-11.

16. Backer JM, Myers MG Jr, Shoelson SE, Chin DJ, Sun XJ, Miralpeix $M$, et al. Phosphatidylinositol $3^{\prime}$-kinase is activated by association with IRS-1 during insulin stimulation. EMBO J. 1992;11(9):3469-79.

17. Czech MP, Corvera S. Signaling mechanisms that regulate glucose transport. J Biol Chem. 1999;274(4):1865-8.

18. Shephard PR, Nave BT, Siddle K. Insulin stimulation of glycogen synthesis and glycogen synthase activity is blocked by wortmannin and rapamycin in 3T3-L1 adipocytes: evidence for the involvement of phosphoinositide 3-kinase and p70 ribosomal protein-S6 kinase. Biochem J. 1995;305(pt.1):25-8.

19. Hayashi T, Wojtaszewski JF, Goodyear LJ. Exercise regulation of glucose transport in skeletal muscle. Am J Physiol. 1997;273(6):E1039-51.

20. Hardie DG, Carling D. The AMP-activated protein kinase: fuel gauge of the mammalian cell? Eur J Biochem. 1997;246(2):259-73.

21. Simoneau JA, Veerkamp JH, Turcotte LP, Kelley DE. Markers of capacity to utilize fatty acids in human skeletal muscle: relation to insulin resistance and obesity and effects of weight loss. FASEB. 1999;13(14):2051-60.

22. Wicklmayr M, Rett K, Fink E, Tschollar W, Dietze G, Mehnert H. Local liberation oh kinins by working skeletal muscle tissue in man. Hormone Metabolism Research. 1988;20(8):535.

23. Youn JH, Gulve EA, Holloszy JO. Calcium stimulates glucose transport in skeletal muscle by a pathway independent of contraction. Am J Cell Physiol. 1991;260(3 Pt 1):C555-61.
24. Holloszy JO, Hansen PA. Regulation of glucose transport into skeletal muscle. Rev Physiol Biochem Pharmacol. 1996;128:99-103.

25. Roberts CK, Barnard RJ, Jasman A, Balon TW. Acute exercise increases nitric oxide synthase activity in skeletal muscle. Am J physiol Endocrinol Metab. 1999;277(2 Pt 1):E390-4.

26. Ropelle ER, Pauli JR, Prada PO, De Souza CT, Picardi PK, Cintra $D E$, et al. Reversal of diet-induced insulin resistance with single bout of exercise in the rat the role of PTP1B and IRS-1 serine phosphorylation. J Physiol. 2007;577:997-1007.

27. Pauli JR, Ropelle ER, Cintra DE, Carvalho-filho MA, Moraes, De Souza CT, et al. Acute physical exercise reverses S-nitrosation of the insulin receptor, insulin receptor substrate 1, and protein kinase B/Akt in dietary induce obese Wistar rats. J Physiol. 2008;586:659-71.

28. Handschin C, Spiegelman BM. The role of exercise and PGC-1 in inflammation and chronic disease. Nature. 2008;454:463-9.

29. Hotamisligil GS, Peraldi P, Budavari A, Ellis R, White MF, Spiegelman BM. IRS-1 mediated inhibition of insulin receptor tyrosine kinase activity in TNF-alpha and obesity-induced insulin resistance. Science. 1996;271(5249):665-8.

30. Dandona P, Aljada A, Bandyopadhyay A. Inflammation: the link between insulin resistance, obesity and diabetes. Trends immunology. 2004;25(1):4-7.

31. Waki $H$, Tontonoz P. Endocrine functions of adipose tissue. Annu Rev Pathol Mech Dis. 2007;2:31-56.

32. Tsukumo DM, Carvalho-Filho MA, Carvalheira JB, Prada PO, Hirabara SM, Schenka AA. Loss-of-function mutation in toll-like receptor 4 prevents diet-induced and insulin resistance. Diabetes. 2007;56(8):1986-8.

33. Foster LJ, Klip A. Mechanism and regulation of GLUT-4 vesicle fusion in muscle and fat cells. Am J Cell Physiol. 2000;279(4):C877-90.

34. Olson AL, Pessin JE. Structure, function, and regulation of the mammalian facilitative glucose transporter gene family. Annu Rev Nutr. 1996;16:235-56.

35. Knowler WC, Barret Connor E, Fowler SE. Reduction in the incidence of type 2 diabetes with lifestyle intervention or metformin. N Engl J Med. 2002;346(6):393-403.

36. McPherson $\mathrm{R}$, Jones PH. The metabolic syndrome and type 2 diabetes: role of the adipocyte. Curr Opin Lipidol. 2003;14(6):549-53.

37. Tuomilehto J, Lindstrom J, Eriksson JG, Valle TT, Hämäläinen $\mathrm{H}$, llanne-Parikka $P$, et al. Prevention of type 2 diabetes mellitus by changes in lifestyle among subjects with impaired glucose tolerance. N Engl J Med. 2001;344:1343-50.

38. Shulman GI. Unraveling the cellular mechanism of insulin resistance in humans: new insights from magnetic resonance spectroscopy. Physiology. 2004;19:183-90.

39. Savage DB, Petersen KF, Shulman GI. Disordered lipid metabolism and the pathogenesis of insulin resistance. Physiol Rev. 2007;87(2):507-20.

40. Waki H, Tontonoz P. Endocrine functions of adipose tissue. Annu Rev Pathol. 2007;2:31-56.

41. Kim JK. Fat uses aTOLL-road to connect inflammation and diabetes. Cell Metab. 2006;4(6):417-9.

42. Milanski M, Degasperi G, Coope A, Morari J, Denis R, Cintra DE. Saturated fatty acids produce an inflammatory response predominantly through the activation of TLR4 signaling in hypothalamus: implications for the pathogenesis of obesity. J Neurosci. 2009;29(2):359-70.

43. Shoelson SE, Lee J, Yuan M. Inflammation and the IKK beta/l kappa N/NF-kappa B axis in obesity- and diet-induced insulin resistance. J Clin Invest. 2003;106:171-6.

44. Hotamisligil GS. Inflammatory pathways and insulin action. Int $\mathrm{J}$ Obes Relat Metab Disord. 2003;27:S53-55.

45. Carvalho-Filho MA, Ueno M, Hirabara SM, Seabra AB, Carvalheira JB, de Oliveira MG, et al. S-nitrosation of the insulin receptor, 
insulin receptor substrate 1, and protein kinase B/Akt: a novel mechanism of insulin resistance. Diabetes. 2005;54(4):959-67.

46. Gross SS, Wolin MS. Nitric oxide: pathophysiological mechanisms. Annu Rev Physiol. 1995;57:737-69.

47. Sugita $H$, Kaneki M, Tokunaga E, Sugita M, Koike C, Yasuhara S, et al. Inducible nitric oxide synthase plays a role in LPS-induced hyperglycemia and insulin resistance. Am J Physiol Endocrinol Metab. 2002;282:E386-94.

48. Carvalho-Filho MA, Ueno M, Carvalheira JB, Velloso LA, Saad MJ. Targeted disruption of iNOS prevents LPS-induced S-nitrosation of IRbeta/IRS-1 and Akt and insulin resistance in muscle of mice. Am J Physiol Endocrinol Metab. 2006;291(3):E476-82.

49. Petersen AM, Pedersen BK. The anti-inflammatory effect of exercise. J Appl Physiol. 2005;98(4):1154-62.

50. Fischer CP, Berntsen A, Perstrup LB, Eskildsen P, Pedersen BK. Plasma levels of interleukin- 6 and $C$-reactive protein are associated with physical inactivity independent of obesity. Scand J Med Sci Sports. 2007;17(5):580-7.

51. Xie L, Lee SY, Andersen JN, Waters S, Shen K, Guo XL, et al. Cellular effects of small molecule PTP-1B inhibitors on insulin signaling. Biochemistry. 2003;42(44):3074-84.

52. Gum RJ, Gaede LL, Koterski SL, Heindel M, Clampit JE, Zinker BA. Reduction of protein tyrosine phosphatase 1B increases insulin-dependent signaling in ob/ob mice. Diabetes. 2003;52(1):21-8.

53. Elchebly M, Payette P, Michaliszyn E, Cromlish W, Collins S, Loy $A L$, et al. Increased insulin sensitivity and obesity resistance in mice lacking the protein tyrosine phosphatase-1B gene. Science. 1999;283(5407):1544-8.

54. Sriwijitkamol A, Coletta DK, Wajcberg E, Balbontin GB, Reyna SM, Barrientes J, et al. Effect of acute exercise on AMPK signaling in skeletal muscle of subjects with type 2 diabetes: a time-course and dose-response study. Diabetes. 2007;56(3):836-48.

55. Pilon G, Dallaire $P$, Marette A. Inhibition of inducible nitric-oxide synthase by activators of AMP-activated protein kinase: a new mechanism of action of insulin-sensitizing drugs. J Biol Chem. 2004; 279(20): 20767-74.

56. Musi N, Fujii N, Hirshman MF, Ekberg I, Fröberg O, Ljungqvist $\mathrm{O}$, et al. AMP-activated protein kinase (AMPK) is activated in muscle of subjects with type 2 diabetes during exercise. Diabetes. 2001;50(5):921-7.

57. Pauli JR, Ropelle ER, Cintra DE, De Souza CT. Efeitos do exercício físico na expressão e atividade da AMPK em ratos obesos induzidos por dieta rica em gordura. Rev Bras Med Esporte. 2009;15(2):99-104.

58. Balon TW, Nadler JL. Evidence that nitric oxide increases glucose transport in skeletal muscle. J Appl Physiol. 1997;82(1):359-63.

59. Kapur S, Marcotte B, Marette A. Mechanism of adipose tissue iNOS induction in endotoxemia. Am J Physiol Endocrinol Metab. 1999;276(4 Pt 1):E635-41.

60. Bisquolo VA, Cardoso CG Jr, Ortega KC, Gusmao JL, TinucciT, Negrao $C E$, et al. Previous exercise attenuates muscle sympathetic activity and increases blood flow during acute euglycemic hyperinsulinemia. J Appl Physiol. 2005;98(3):866-71. 